\title{
Modeling of respiratory network: to sigh or not to sigh
}

\author{
Tatiana Dashevskiy ${ }^{1 *}$, Jan-Marino Ramirez ${ }^{1,2}$ \\ From 24th Annual Computational Neuroscience Meeting: CNS*2015 \\ Prague, Czech Republic. 18-23 July 2015
}

The Pre-Bötzinger Complex (PreBötC), a medullary brainstem region, is essential for generating breathing. Isolated in a transverse slice preparation, the preBötC continues to generate under normal conditions "fictive eupneic activity" and at a lower frequency also "fictive sighs". The mechanisms generating the periodicity of fictive sighs as well as its intrinsic nature are largely unknown. Based on the experimental observations such as 1) sigh has the biphasic shape characterized as eupneic breath interrupted by augmentation with a second peak of activity, 2) the biphasic shape persists after blockage of inhibitory synapses, 3 ) the network is heterogeneous, we model PreBötC network that reproduces both types of activities. The model contains three types of neurons: intrinsically tonic spiking, intrinsic bursting neurons and intrinsic quiescent. Neurons within the network are sparsely connected through randomly distributed excitatory synapses. In this model we propose that the mechanism of sigh generation is based on slow oscillations generated by glia. Moreover, the model predicts that depending on the modularity state of the system, the network exhibits sighs, does not exhibit sighs and shows only eupneic activity, or shows bi-stable activity meaning that sighs can be triggered between "on" and "off" states by short perturbation. The bistability depends on slow calcium oscillations. The network model predicts that the presence of IP3-like channels is necessary to produce "sigh" behavior and to mimic transitions between activity states caused by neuromodulators. We analyze the model dynamics and describe dose-response curve to neuromodulator such as norepinephrine. Theoretical data are similar to experimental

\footnotetext{
* Correspondence: tatiana.dashevskiy@seattlechildrens.org

${ }^{1}$ Center for Integrative Brain Research, Seattle Children's Research Institute, Seattle, WA, USA

Full list of author information is available at the end of the article
}

data from in vitro brain slice preparations and in vivo anesthetized mice.

\section{Authors' details \\ ${ }^{1}$ Center for Integrative Brain Research, Seattle Children's Research Institute, Seattle, WA, USA. ²Department of Neurological Surgery, University of Washington, Seattle, WA, USA.}

Published: 18 December 2015

\section{doi:10.1186/1471-2202-16-S1-P48}

Cite this article as: Dashevskiy and Ramirez: Modeling of respiratory network: to sigh or not to sigh. BMC Neuroscience 2015 16(Suppl 1):P48.
Submit your next manuscript to BioMed Central and take full advantage of:

- Convenient online submission

- Thorough peer review

- No space constraints or color figure charges

- Immediate publication on acceptance

- Inclusion in PubMed, CAS, Scopus and Google Scholar

- Research which is freely available for redistribution

Submit your manuscript at www.biomedcentral.com/submit

\section{() Biomed Central}

